\title{
Accumulation of Pesticides in Tomato Packinghouse Wastewater and the Influence of Integrated Pest Management on Reducing Residues
}

\author{
James W. Rushing, \\ Wilton P. Cook, ${ }^{2}$ and \\ Larry Spell ${ }^{3}$
}

Additional index words. Lycopersicon esculentum.

Summary. Water analyses from six commercial tomato packinghouse dump tanks in South Carolina revealed that metal and pesticide residues accumulate in the dump-tank water during daily operation. The amount that accumulated varied widely as follows: Asana (esfenvalerate), 0.3 to $13.8 \mathrm{ppb}$; Bravo (chlorothalonil), 0.1 to 2.7 ppm; copper, 2.0 to $7.3 \mathrm{ppm}$; and manganese, 0.1 to $2.5 \mathrm{ppm}$. Contamination appeared to be lowest when growers implemented integrated pest management (IPM) during production. In a subsequent controlled study, tomatoes were produced under the following pest-management practices: IPM protocol with pesticide applications based on scouting reports, modified IPM with one arbitrary pesticide application at bloom, and weekly pesticide applica-

${ }^{1}$ Associate professor, Clemson Uwiversity, Coastal Re search and Education Center, Charleston, SC 29414.

${ }^{2}$ Professor, Clemson University, Coastal Research and Education Center, Charleston, SC 29414.

${ }^{3}$ Chemist, Medical University of South Carolina, Agromedicine Center, Charleston, SC 29425.

Technical contribution no. 4078 of the South Carolina Agricultural Experiment Station, Clemson Univ. Clemson, SC 29634. Reference to a firm or trade name does not imply endorsement over firms or products not mentioned. The cost of publishing this paper was defrayed in part by the payment of page charges, Under postal regulations, this paper therefore must be hereby marked advertisement solely to indicate this fact. 
tion regardless of pest pressure. In a commercial packinghouse operation, the water used for tomatoes that were produced with a weekly spray schedule had about 2 to 10 times the amount of pesticide and metal residues found in the water used for tomatoes grown under IPM protocol. Modified IPM protocol resulted in intermediate levels of residues. These results confirm that IPM field practices can reduce residues in tomato packinghouse wastewater. bout 400 million $\mathrm{kg}$ of pesticides is used annually in the United States (Freshwater, 1988; Gianessi and Anderson, 1993; Keystone, 1993). Chemicals that are applied to horticultural crops in the field may be carried to packing and processing facilities on the commodity surface where operations that require water can remove the residue (Gonzalez et al., 1989). In most tomato packinghouses, several thousand gallons of water are used daily in dump tanks. Disposal of this water is of concern because of the potential for contamination of surface or underground small-scale dump tank simulating

A water reservoirs, especially in areas with sandy soils (Mulls et al., 1989; Romander, 1988). Despite any environmental concern, effluent from many tomato packinghouses is discharged directly onto the ground. Regulatory agencies in Florida confirmed that wastewater from 17 fruit and vegetable packing facilities tested was a potential source of groundwater contamination (Howard, 1988 ). Tomato packinghouse effluent in particular contained several contaminants in high enough concentrations to warrant environmental concern, and most of the packing facilities received warnings that they were in violation of wastewater standards (Howard, 1989).

The Florida experience suggested that we should determine if a similar situation exists in South Carolina and what measures can be taken to prevent groundwater contamination. In 1990, South Carolina had 892 reports of groundwater contamination, 58 of which involved agricultural chemicals (Bailey, 1991 ). In a preliminary study, we found that metal and pesticide residues accumulate in commercial tomato packinghouse dump tanks. Packers of fruit that were produced using integrated pest management (IPM) protocol appeared likely to have less pesticide residue in wastewater than those of fruit grown using non-IPM procedures.. This led to our second objective of determining the influence of different preharvest pest-management programs, including IPM, on the extent of tomato dump-tank contamination.

\section{Materials and methods}

Commercial packinghouse survey Six tomato-packing facilities in the coastal region of South Carolina were surveyed. All packinghouses were equipped with dump tanks. As tomatoes emerged from the tank on a conveyor, they were rinsed with water that was pumped from the dump tank through nozzles positioned over the conveyor. This rinse water then flowed back into the dump tank, so that the water used in packing tomatoes is continuously recirculated in a closed system. All of the packinghouses surveyed used this system, which is common throughout the tomato industry in the United States.

The volume of water in each dump tank was calculated. and each packer provided information on the amount of fruit packed
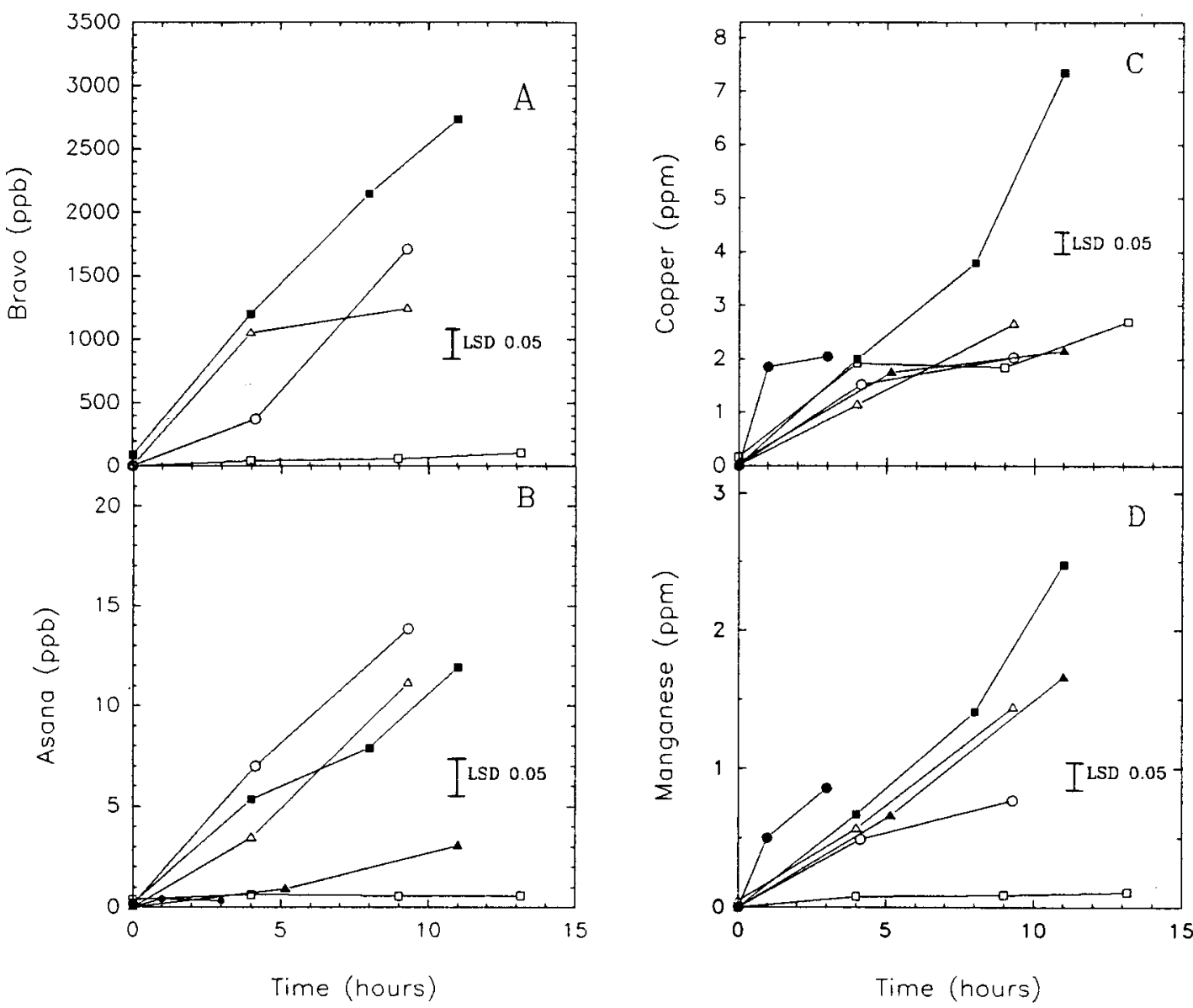
each day of the study. This allowed us to calculate the approximate ratio of fruit weight to water volume used in commercial tomato packinghouses.

In three of the packinghouses, the owners reported that they only packed fruit produced on their own farms, while the other three packed for several growers. Growers ing their pesticide appli-

Fig. 1. Accumulation of (A) Bravo, (B) Asana, (C) copper, and (D) manganese in tomato packing house dumptank water during 1 day of operation. Each data point represents the average of two water samples. Symbols indicate different packinghouses. Absence of symbols indicates no detectable residues. The LSD was used to compare within each packing house over time. were interviewed regard- 
cation protocols; however, responses from growers were general, revealing only their use of scouting and general adherence to IPM protocol. We confirmed definitely that one growerowned packinghouse was on a full IPM program. Water-quality data from this packinghouse are discussed later relative to conditions in a packinghouse that had many growers that did not strictly adhere to IPM protocol.

Duplicate water samples were collected from each of the six packinghouse dump tanks before the beginning of daily operation and at selected intervals during the day (Fig. 1). Duplicate samples also were collected from each water source, including private wells and municipal water.

Influence of IPM on pesticide residues in a simulated dump tank

Experimental fruit production. 'Sunny' tomatoes were grown at the Coastal Research and Education Center according to recommended commercial practices (Cook et al., 1985 ). Three pest-management protocols were implemented: 1 ) complete IPM program in which pesticides were applied only as needed based on field scouting; 2) modified IPM, which included an arbitrary pesticide application at bloom with subsequent applications based on complete IPM protocol; and 3) a calendar spray schedule with no regard for scouting reports. The spray application schedule for all plots is shown (Table 1 ). An unsprayed control plot was included.

Each experimental plot consisted of four rows bordered on each side by a guard row. Rows were $35 \mathrm{~m}$ long, spaced $1.8 \mathrm{~m}$ apart, with a plant spacing of $0.6 \mathrm{~m}$ within rows. A randomized complete-block design with three replications was used in this study.

Six spray applications were applied from bloom until harvest in the calendar spray schedule (Table 1). The first five applications contained Asana (0.04 kg a.i./ha) and Manzate 200DF ( $1.2 \mathrm{~kg}$ a.i./ha). The final application contained Asana at the above rate plus Bravo 720 (1.3 liter a.i./ha). For all applications, pesticides were mixed together and applied with about 925 liters water/ha without surfactant. Unnecessary applications for the IPM and the modified IPM protocols are indicated in Table 1.

Simulated dump tanks. Based on measurements made in commercial packinghouses and information supplied by packers, the average ratio of fruit weight to dump-tank water volume was calculated to be about $12 \mathrm{~kg}$ tomatoes/liter water. Three small dump tanks (22-liter capacity) were prepared. The dump tank water was heated to $43 \mathrm{C}$ and chlorinated to 100 ppm, and the $\mathrm{pH}$ was adjusted to 6.8 as recommended by Showalter (1993).

Tomatoes were harvested on two dates (Table 2). After harvest, fruit were weighed and, from each field plot, $264 \mathrm{~kg}$ of fruit was passed through a dump tank. The fruit were allowed to stay in the dump tank for 3 min with occasional agitation to simulate the commercial procedure.

Water sample. Duplicate water samples were collected from the simulated dump tank before any fruit were dumped, then duplicates were collected again at the end of the dumping procedure. The entire procedure was repeated once for each of the three fieldplot replications.

Water sample handling

In accordance with U.S. Environmental Protection Agency (EPA) guidelines (EPA, 1986), containers (1liter capacity) and lids were washed in hot water with Alconox; rinsed three times with tap water, once with $10 \%$ nitric acid, and three times with deionized water; and allowed to air dry. Labels were applied containing the

Table 1. Pesticide application schedule for the study on the influence of integrated pest management (IPM) on chemical residues in a simulated dump tank.

\begin{tabular}{lccc}
\hline & \multicolumn{3}{c}{ Pest-management protocol } \\
\cline { 2 - 4 } Application & IPM & Modified IPM & Calendar spray \\
\hline First & NS $^{z}$ & 17 May & 17 May \\
Second & NS & NS & 22 May \\
Third & 29 May & 29 May & 29 May \\
Fourth & NS & NS & 5 June \\
Fifth & 12 June & 12 June & 12 June \\
Sixth & NS & NS & 20 June \\
\hline
\end{tabular}

${ }^{2} \mathrm{NS}=$ no spray packinghouse code, sample number, and date. Containers were filled to capacity, sealed using aluminum foil to line the inside of the lid, then placed on ice in an insulated chest for transport to the laboratoty where they were stored in darkness at $3 \mathrm{C}$ until the chemical extractions and analyses were completed. Samples spiked with Bravo and Asana were placed in storage with the treatment samples. Additional controls consisted of deionized water that was subsequently distilled.

\section{Chemical residue analyses}

Extraction and analysis of Bravo and Asana residues in water were conducted in the Agromedicine laboratory at the Medical Univ. of South Carolina according to EPA (1986). The laboratory was not equipped for analyzing the active ingredient in Manzate (ethylene bisdithio-carbamate ), therefore zinc and manganese were analyzed. The content of copper, manganese, and zinc in water samples was determined at Clemson Univ. Agricultural Services Laboratory using the inductively coupled plasma technique (Velmer, 1978; Velmer and Kniseley, 1974). All residue analyses were completed within 45 days after the sampling date.

\section{Results and discussion}

\section{Commercial packinghouse survey}

The maximum amount of chemical residues found in dump-tank water at the end of daily operations were as follows: Bravo, 2735 ppb; Asana, 13.8 ppb; copper, 7.35 ppm; and manganese, $2.5 \mathrm{ppm}$ (Fig. 1). Manganese and copper data for one of the packinghouses, designated by a closed circle, reflect only $3 \mathrm{~h}$ of packing because harvest was terminated due to rain. The data represent 1 day of operation for each of the six packinghouses. Data collected for a second day of packing operation showed similar increases in residues over time (data not shown).

Recovery from spiked samples was $58 \%$ for Asana and $97 \%$ for Bravo. There were no detectable residues of these pesticides in deionized and distilled water controls or in the water samples from private wells and municipal water.

The packinghouse represented by an open square in Fig. 1, which has consistently lower residues in dumptank water compared to other packinghouses, was a grower-owned facility that packed only the tomatoes that 
it produced. This grower participated in a full-IPM program sanctioned by the South Carolina Tomato Association, which provided a twice-weekly scouting program and recommendations for pesticide application. In contrast, the packinghouse represented by closed squares in Fig. 1 packed for 14 different growers, few of which participated in the full-IPM program. Accumulation of residues in water from the non-IPM packinghouse (closed square Fig. 1 ) was dramatically higher than in the full-IPM packinghouse (open square Fig. 1). This observation was the basis for continuing our investigation on the relationship between IPM and residues in packinghouse wastewater.

Influence of IPM on pesticide residues in a simulated dump tank

Tomatoes harvested on 12 Tune did not leave detectable residues of Bravo in simulated dump tank water. The amounts of Asana, zinc, and manganese were significantly higher in water used for fruit on the calendar spray schedule compared to fruit produced under a full IPM program. Fruit prduced under a modified IPM protocol resulted in intermediate residue levels (Table 2). Spray applications scheduled for 12 June were applied after the completion of harvest on that date (Table 2).

Tomatoes harvested on 22 June did not leave detectable residues of Bravo in dump-tank water if grown under full-IPM or modified-IPM protocols. However, there was $2.40 \mathrm{ppb}$ Bravo in the water used for fruit grown under a calendar spray program [Table 2). There was a 10 -fold increase in the amount of Asana residues in water used for calendar spray fruit compared to fruit produced using full-IPM protocol. Calendar spray applications also resulted in higher zinc and manganese levels in dump-tank water after the second harvest, similar to the values found with the first harvest (Table 2).

Nonsprayed control plots did not yield a sufficient quantity of marketable fruit to conduct the simulated dump-tank study. There were substantially more residues detected in some commercial dump tanks than in our simulated dump tank study (Table 2, Fig. 1). Several factors could contribute to this disparity. First, it is common for commercial tomato producers in South Carolina to spray immediately after a rain, regardless of

Table 2. Residues in water samples from the simulated dump-tank study after dumping tomatoes produced under different pest-management protocols and harvested on two dates. Source water contained no detectable chlorothalonil (Bravo) or esfenvalerate (Asana); however, it contained $0.04 \mathrm{ppm}$ zinc and $0.10 \mathrm{ppm}$ manganese.

\begin{tabular}{|c|c|c|c|}
\hline \multirow{2}{*}{$\begin{array}{l}\text { Pesticide } \\
\text { residue }\end{array}$} & \multicolumn{3}{|c|}{ Pest-management protocol } \\
\hline & IPM ${ }^{2}$ program & Modified IPM & Calendar spra \\
\hline \multicolumn{4}{|c|}{ Harvest, 12 Iune 1990} \\
\hline Bravo (ppb) & $\mathrm{ND}^{y}$ & ND & ND \\
\hline Asana (ppb) & $0.12 \mathrm{a}^{\mathrm{x}}$ & $0.24 \mathrm{~b}$ & $0.31 \mathrm{c}$ \\
\hline $\mathrm{Zn}(\mathrm{ppm})$ & $0.20 \mathrm{a}$ & $0.44 \mathrm{~b}$ & $0.58 \mathrm{c}$ \\
\hline $\mathrm{Mn}(\mathrm{ppm})$ & $0.13 \mathrm{a}$ & $0.23 \mathrm{~b}$ & $0.24 \mathrm{~b}$ \\
\hline Bravo (ppb) & ND & ND & $\mathrm{ND}$ \\
\hline Asana (ppb) & $0.31 \mathrm{a}$ & $0.47 \mathrm{~b}$ & $3.19 \mathrm{c}$ \\
\hline $\mathrm{Zn}(\mathrm{ppm})$ & $0.33 \mathrm{a}$ & $0.35 \mathrm{a}$ & $0.61 \mathrm{~b}$ \\
\hline $\operatorname{Mn}(\mathrm{ppm})$ & $0.43 \mathrm{a}$ & $0.45 \mathrm{a}$ & $0.70 \mathrm{~b}$ \\
\hline
\end{tabular}

IPM = integrated pest management.

${ }^{y} N D=$ no detectable residue.

${ }^{x}$ Means within rows separated by LSD at $P=0.05$. Lowest detectable limits were calculated at about 0.2 ppb for Bravo and 0.1 ppb for Asana based on interpolation of results of standards.

pest pressure or scouting reports. Bravo and Asana, respectively, require $\mathrm{O}$ days and 1 day from the last application until harvest. Growers may apply these chemicals one afternoon and harvest the fruit the following morning, which we believe would leave a significant amount of residue on the fruit surface. Rainfall during the time the controlled study "was conducted was as follows: on $5,10,15,28$, and 29 May the rainfall was $0.03,2.46,0.08,0.25$ and $1.65 \mathrm{~cm}$, respectively; while on 4,10 , and 16 June it was 1.85, 0.10 and 3.86 $\mathrm{cm}$. Rainfall data alone for the controlled study probably do not account for the lower residues observed compared to commercial operations, for which no rainfall data are available.

Secondly, the ratio of fruit weight to water volume, which we used for our simulated dump-tank study, was an average of ratios estimated from all commercial packinghouses. It is conceivable that we may have underestimated this ratio.

Finally, growers actually may apply pesticides more frequently than they are willing to admit. In our controlled IPM study, we were very careful to apply the minimum amount of chemicals that we believed was required.

\section{Conclusions}

Our first objective of determining the extent of chemical residue accumulation in tomato packinghouse wastewater was satisfied. In this study, dump-tank water appeared to remove pesticides effectively from the surface of tomatoes in commercial packing- houses based on the amounts of residues that accumulated in the water.

Our second objective of investigating the influence of IPM on residue accumulation in a simulated dump tank also was met. Implementing IPM during tomato production reduced the amounts of Bravo, Asana, zinc, and manganese that accumulated in a smallscale-tomato dump-tank study.

The amount $\sim$ of pesticide and metal residues that accumulate in tomato packinghouse wastewater is sufficient to warrant concern about disposal of that water (Howard, 1988, 1989). Unfortunately, federal and state regulatory agencies do not have an adequate database from which to provide recommendations for effective management of agrichemicals and the protection of groundwater, and no industry-wide recommendations for residue tolerances on wastewater disposal are currently available (Freshwater. 1988). The problem is intensified by the vast improvements in the sensitivity of detection procedures and the insistence by some organizations that all agricultural wastewater must conform to drinking-water standards (Bolusky and Regelbrugge, 1992; Whitcraft, 1988).

\section{Literature Cited}

Bailey, A. 1991. Groundwater quality a big issue for state scientists. In: E. Hall (ed.). South Carolina agriculture tomorrow. Clemson Univ., S.C. Agr. Expt. Sta.

Bolusky, B. and C. Regelbrugge. 1992. Political perspective on water quality impact. HortTechnology 2:80-82. 
Cook, W. P., C.E. Drye, and R.P. Griffin. 1985. Commercial tomato production in South Carolina. Clemson Univ. Coop. Ext. Circ. 625.

Fassel, V.A. 1978. Quantitative elemental analysis by plasma emission spectroscopy. Science 202:183-191.

Fassel, V.A. and R.N. Kniseley. 1974. Inductively coupled plasmas. Anal. Chem. 46:1155-1164.

Freshwater Foundation. 1988. Recommendations from the conference Agricultural Chemicals and Groundwater Protection: Emerging Management and Policy. St. Paul, Minn., October 1987.

Gianessi, L.P. and J.E. Anderson. 1993. Pesticide use trends in U.S. agriculture, 1979-1992. Natl. Center for Food and Agr. Policy, Washington, D.C. Discussion paper PS-93- 1.

Gonzalez, A. R., D.R. Davis, E.R. Elkins, and E.S. Kim. 1989. Reduction of ethylenethio urea residues in canned spinach. HortScience 24:990-992.

Howard, D.F. 1988. Preliminary report on exceedances of water quality standards at fruit and vegetable packing facilities 19861988. Metropolitan Dade County Dept. of Environ. Resources Mgt., Miami.

Howard, D.F. 1989. Preliminary report on water quality analysis of effluent produced by tomato packing operations in Dade County. Metropolitan Dade County Dept. of Environ. Resources Mgt., Miami.

Keystone Center. 1993. The Keystone national policy dialogue on food safety and pesticides. Keystone Center, Keystone, Colo.

Mulls, D.J., R.E. Hermanson, and R.C. Maxwell. 1989. Pesticide movement in soils-Groundwater protection. Washington State (Pullman) Coop. Ext. Bul. E8 1543.

Romander, L. 1988. Groundwater logic. Agrichemical Age 32:26-29.

Showalter, R.K. 1993. Postharvest water intake and decay of tomatoes. HostTechnology 3:97-98.

U.S. Environmental Protection Agency. 1986. Method no. 2-Determination of chlorinated pesticides in groundwater by GC/EDC. EPA Environ. Monitoring and Support Lab., Cincinnati.

Whitcraft, B. 1988. Overdue or overkill? Agrichemical Age 32:6-12. 